\title{
The tolerance of tomato potato psyllid life stages to ethyl formate
}

\author{
L.E. Jamieson, M.J. Griffin, N.E.M. Page-Weir, S.P. Redpath, A. Chhagan, P.G. Connolly and \\ A.B. Woolf
}

The New Zealand Institute for Plant \& Food Research Limited, Private Bag 92169, Auckland 1142, New Zealand

Corresponding author: lisa.jamieson@plantandfood.co.nz

\begin{abstract}
Methyl bromide fumigation became mandatory for capsicums and truss tomatoes exported to Australia after tomato potato psyllid (TPP) was detected in 2006 in New Zealand. Methyl bromide detrimentally affects product quality by increasing rots and the browning of the green stems. An alternative being tested is ethyl formate (EF) and carbon dioxide, commercially available as VAPORMATE ${ }^{\circledR}$. This study examined the tolerances of different life stages of TPP to EF. Eggs were considerably more tolerant of EF than adults and nymphs. Complete elimination of egg hatch was achieved after a 1-h exposure to $1.19 \%$ EF. In contrast, all nymphs and adults were killed after a 1-h exposure to $0.12 \%$ and $0.06 \%$ EF, respectively. Assessment of egg mortality was altered to better reflect the post-hatch treatment effects on nymph survival. In a subsequent egg age tolerance trial, mean lethal concentrations for $99 \%$ mortality ranged from ca $1 \%$ EF for young and older eggs to ca $1.5 \%$ EF for mid-aged eggs.
\end{abstract}

Keywords Bactericera cockerelli, VAPORMATE ${ }^{\circledR}$, disinfestation, fumigation, capsicum, truss tomato, tamarillo, ethyl formate, carbon dioxide.

\section{INTRODUCTION}

In 2006 tomato/potato psyllid (TPP; Bactericera cockerelli) was first recorded in New Zealand. Subsequently, because of the biosecurity risk, fumigation with methyl bromide became mandatory for capsicums and tomatoes being exported to Australia (MPI 2014). This was later removed for loose tomatoes with no calyx and replaced by a systems approach using low pest prevalence in the greenhouse and brushing of the tomatoes. However, truss tomatoes and capsicums still require methyl bromide fumigation before export. This treatment detrimentally affects the quality of the product, increasing rots and the browning of the green stems. Many exporters are simply no longer exporting capsicums and truss tomatoes, as the quality impacts of methyl bromide mean that it is no longer economically viable. In addition, methyl bromide is being phased out and may soon become more expensive or even commercially unavailable. Therefore, phytosanitary alternatives that maintain good fruit quality are required.

Alternatives can be in the form of a single treatment or a systems approach using multiple independent risk reduction measures. Alternative options include high pressure water 
washing (HPW), or heat and cold treatment, but fumigation of the final packed product is a preferred option for many. Ethyl formate (EF) is a 'generally recognised as safe' (GRAS) compound and is therefore considered safe for use with human food and may be excluded from mandatory premarket approval (US FDA 2015). It has been used for a number of years as a commercial disinfestation treatment for pineapples and bananas in the Philippines and is beginning to be used commercially for blueberries, persimmons, feijoas and kiwiberries in New Zealand (Brian Hamilton, BOC Gases, personal communication). EF was identified as a promising disinfestation treatment for a range of fresh produce (Jamieson et al. 2009). EF is commercially available in New Zealand as VAPORMATE ${ }^{\circledR}$, which is $16.7 \mathrm{wt} \%$ EF with 83.3\% $\mathrm{CO}_{2}$ (Ryan \& Bishop 2003).

This paper outlines initial trials to develop $\mathrm{EF}+\mathrm{CO}_{2}$ as a postharvest disinfestation treatment for capsicums and truss tomatoes, by determining which life stage of TPP is the most tolerant to $\mathrm{EF}+\mathrm{CO}_{2}$ and what lethal $\mathrm{EF}$ concentrations are required to control TPP.

\section{MATERIALS AND METHODS \\ Setting up TPP}

Tomato leaves ('Moneymaker') were collected from 8-week-old plants for inoculation with TPP. Leaves that were three to four nodes below the growing tip were selected. The cut end of each leaf was then placed in a 5 - $\mathrm{ml}$ glass vial of water and the top enclosed with cotton wool. Each leaf was then placed within a graduated plastic container $(10 \mathrm{~cm}$ length $\times 8-11 \mathrm{~cm}$ width $)$, with mesh at each end to allow for ventilation and later for fumigation. Each container was set up with one of the following TPP life stages: eggs, early nymphs, late nymphs or adults. The sex ratio of adults was determined by sexing 670 individuals, of which 354 were females and 316 were males (53:47 sex ratio). To obtain eggs and early nymphs, fifty adult TPP were collected using a vacuum aspirator into test tubes from a colony maintained on capsicum plants at Plant \& Food Research, and placed in each container with a single tomato leaf to lay eggs for 7 days. After 7 days, all adults were removed and the leaves were placed at $20^{\circ} \mathrm{C}$. Containers set up in this way 2 weeks before treatment had egg hatch resulting in early instar nymphs at the time of treatment. Containers set up 7 days before treatment had eggs of various ages (1-7 days old) for treatment. Before treatment, each leaf was assessed to ensure that there were $100+$ nymphs, or eggs, on each leaf. Late nymphs were easily transferred by hand using a fine-tipped paintbrush. Using this method, 100 late instar nymphs were placed on each leaf in a container. A vacuum aspirator was used to collect 100 adults of mixed sex. The adults were then placed into each container with a single tomato leaf.

\section{Treatments}

The EF treatments were carried out in the Volatile Treatment Facility (VTF) at Plant \& Food Research in Auckland. Fourteen identical 76.8-litre steel gas-tight chambers were used for this trial in a controlled temperature room at $13^{\circ} \mathrm{C}$. The amount of EF and $\mathrm{CO}_{2}$ delivered to each chamber was controlled by the user input into the computer program and was delivered using the same ratio of $\mathrm{CO}_{2}$ : EF as VAPORMATE ${ }^{\circledR}$. $\mathrm{A} \mathrm{CO}_{2}$ gas stream (10 litres/min) was passed through a heated bead bath $\left(75^{\circ} \mathrm{C}\right)$ and liquid $\mathrm{EF}$ was delivered using a micro-dispenser into the heated gas stream. The gas was again passed through the heated bead bath to volatilise the EF before delivery to the chamber. The chambers filled automatically and consecutively and were purged of EF once the treatment time was completed. $\mathrm{EF}$ and $\mathrm{CO}_{2}$ were monitored in each chamber, with $50-\mu \mathrm{l}$ samples taken from the chamber and injected into a gas chromatograph unit. For all trials below, mortalities of EF-treated TPP were compared with untreated and $\mathrm{CO}_{2}$-treated TPP.

\section{Trial 1: Defining dose rates}

An experiment with only one replicate was carried out to define the mortality response of various life stages of TPP exposed to six concentrations of $\mathrm{EF}+\mathrm{CO}_{2}$ (EF) for each of four durations $(1,2,3,4 \mathrm{~h})$ at $13^{\circ} \mathrm{C}$ in 76 -litre chambers. This 
was to enable an appropriate duration and range of concentrations to be selected for the TPP life stage tolerance trial.

\section{Trial 2: Life stage tolerance trial}

Based on the results from the dose rate experiment, all life stages of TPP were exposed to a 1-h treatment of one of 10 concentrations of $\mathrm{EF}+\mathrm{CO}_{2}$ at $13^{\circ} \mathrm{C}$ in 76-litre chambers. Nymphs and adults were exposed to targets of $0.05,0.1$, 0.15 or $0.2 \% \mathrm{EF}$ and the more tolerant egg stage was exposed to targets of $0.5,0.8,1.0,1.3,1.6$ or $2.0 \%$ EF. Four replicates (i.e. chambers) of each treatment were carried out.

\section{Trial 3: Egg age tolerance trial}

The tolerance of three egg ages to EF was tested to determine if there was a significant difference in tolerances based on age. At $20^{\circ} \mathrm{C}$, Tran (2012) found that on average, TPP took 7 days from egg lay to develop and first instar nymph hatch. With a 7-day development period, eggs were classified into three groups: early (1- to 2-day-old eggs), mid (3- to 4-day-old eggs), late (5- to 6-dayold eggs) for fumigation treatment. Adult TPP were collected from the colony and 100 (ca 50:50 male:female) were placed into each container with a single tomato leaf as described above. Containers were placed within a $20^{\circ} \mathrm{C}$ room with 16:8 h light:dark to allow for egg lay. Setup up of the adults on the leaves was staggered at 2, 4 and 6 days before treatment. Adults were left on the leaf for 2 days before being removed and then all eggs ages were treated on the same day within the ventilated container. Eggs were exposed for $1 \mathrm{~h}$ to EF target concentrations of $0.5,0.8,1.0,1.3$, 1.6 or $2.0 \%$ EF. Three replicates (i.e. chambers) of each treatment were carried out.

\section{Mortality assessments}

After treatment, the TPP were held at $20^{\circ} \mathrm{C}$ and the numbers of live and dead nymphs or adults were recorded 1 day after treatment. Any nymphs or adults that had movement when gently prodded with a fine-tipped paintbrush were classified as live. Those that showed no movement were classified as dead. Leaves with treated and untreated TPP eggs were kept at $20^{\circ} \mathrm{C}$ for 14 days before assessment. During that time, the water in the vials was replenished as needed, and fresh non-infested leaves provided in each pot for any hatching nymphs to feed upon. In trials 1 and 2, eggs were classified as hatched (live) if a newly emerged nymph was present (live or dead), or unhatched (dead) if the entire egg remained. After assessing trials 1 and 2 it was noted that many of the nymphs in the treated samples were dead, whereas in untreated samples nymphs were mostly alive, indicating that EF treatment may have had an effect on nymph survival once they had hatched. Therefore, in trial 3 TPP were classified as surviving treatment (live) only if live nymphs were present, and dead nymphs, which may have hatched and died due to the effect of the treatment, were classified as dead along with unhatched eggs.

\section{Statistical analysis}

The TPP mortality data were analysed and are presented in figures based on actual EF concentrations measured rather than target calculated concentrations. The effect of EF on the mortality of TPP was analysed using a robust version of the Generalized Linear Model (GLM) capabilities (Hastie \& Pregibon 1992) in $\mathrm{R}$ version 2.15.2 (R Core Team 2013). Variance was assumed proportional to that for a binomial distribution. The analysis assumed that the form of dependence of mortality on concentration was that given by a complementary-log-log model, with concentration as the explanatory variable. The assumed form of response was $\log (-\log$ $(1-p))=a+b c$, where $\mathrm{p}=$ expected mortality, and $c=$ concentration of EF. From the derived coefficients, the $\mathrm{LC}_{99}$ (lethal concentration for 99\% mortality) was calculated, with adjustment for sources of mortality other than EF. Two possible sources of extraneous mortality were considered: handling, and treatment with $\mathrm{CO}_{2}$. The mortalities attributed to these sources were compared using a simpler binomial GLM and found not to be significantly different. Therefore, the handling control and treatment control mortality data were combined and used as the 
control mortality, $\mathrm{cm}$, in the calculation of the $\mathrm{LC}_{99}$ values, $\mathrm{cm}+(1-\mathrm{cm}) \times 0.99$. The geometric means of the four replicates for each life stage were calculated along with a $95 \%$ confidence interval. Non overlap of $95 \%$ confidence intervals is evidence of a difference at approximately $\mathrm{P}=0.01$. For mortality response figures (Figures 1, 2 and 3 ), non-parametric loess fits (Cleveland et al. 1992) were calculated and plotted on an arcsine scale in R. Smooth lines were drawn through the mean percentage mortality points for each TPP life stage-treatment duration combination after exposure to $\mathrm{EF}+\mathrm{CO}_{2}$, at each concentration. The error bars represent the root-mean-square of the errors of the fit and are applicable over the entire mortality range, which would not be the case if calculated on a binomial scale.

\section{RESULTS}

\section{Trial 1: Defining dose rates}

All 3253 adults, 2116 late nymphs and 4931 early nymphs exposed to EF treatments (0.15 - 2.55\% EF) were killed. This compared with mortality rates of between 0 and $25 \%$ for untreated and $\mathrm{CO}_{2}$-treated adults and nymphs. Eggs were the most tolerant life stage to EF treatment. Complete prevention of egg hatch ( $100 \%$ mortality) was achieved using a 1-h exposure to $1.8 \% \mathrm{EF}$, a 2-h exposure to $1.1 \% \mathrm{EF}$, a 3 -h exposure to $1.7 \%$ and a 4 -h exposure to $0.6 \%$ EF (Figure 1). Calculated lethal concentrations for $99 \%$ mortality for 1-4 h treatments were between 0.51 and $1.87 \%$ (Table 1). A 1-h treatment time was selected for the replicated life stage tolerance trial.

Table 1 Estimated lethal concentration (\%) calculated to achieve $99 \%$ mortality ( LC $_{99}$ ) of tomato potato psyllid eggs (of mixed age) using concentrations between 0 and $2.6 \%$ ethyl formate (EF).

\begin{tabular}{ccr}
\hline Treatment time $(\mathrm{h})$ & $\mathrm{LC}_{99}$ & $\mathrm{n}$ \\
\hline 1 & 1.15 & 955 \\
2 & 0.62 & 809 \\
3 & 1.82 & 1176 \\
4 & 0.51 & 953 \\
\hline
\end{tabular}

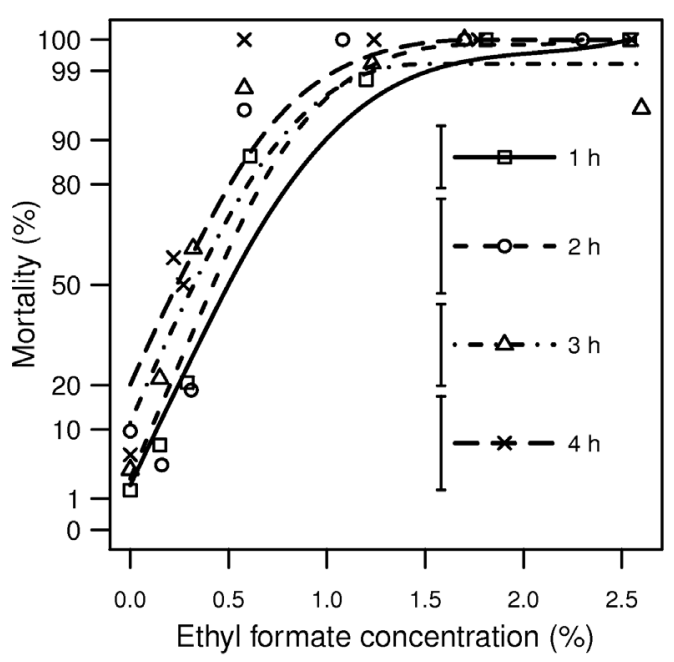

Figure 1 Mortality (\%) of tomato potato psyllid eggs to ethyl formate treatment using different exposure times $(\mathrm{h})$. For each point, $\mathrm{n}=20-328$.

\section{Trial 2: Life stage tolerance trial}

This replicated trial confirmed the egg stage was the most tolerant life stage to EF treatment. Complete kill of eggs was achieved after a 1-h exposure to $1.19 \%$ EF (Figure 2). In contrast, all nymphs and adults were killed after a 1-h exposure to only $0.12 \%$ and $0.06 \%$ EF, respectively (Figure 2). Calculated mean lethal concentrations for $99 \%$ mortality $\left(\mathrm{LC}_{99}\right)$ for eggs and nymphs were $0.81 \%$ and $0.07 \%$, respectively (Table 2 ). LC $_{99}$ values were not calculated for adults, as there were not enough mortality points below $100 \%$ to provide a statistically robust value.

\section{Trial 3: Egg age tolerance trial}

Mid aged eggs (3-4 days old) tended to be more tolerant to EF treatment (Figure 3) requiring an estimated $1.52 \%$ EF for $1 \mathrm{~h}$ to achieve $99 \%$ mortality (Table 3). This compared to mean lethal estimates of $0.98-1.05 \% \mathrm{EF}$ for $1 \mathrm{~h}$ to achieve $99 \%$ mortality of younger (1-2 days old) and older (5-6 days old) eggs (Table 3). Although in practical terms $1 \% \mathrm{EF}$ and $1.5 \% \mathrm{EF}$ is a notable difference, these mean lethal concentration estimates $\left(\mathrm{LC}_{99} \mathrm{~s}\right)$ for different egg stages were not significantly different $(\mathrm{P}>0.01)$. 


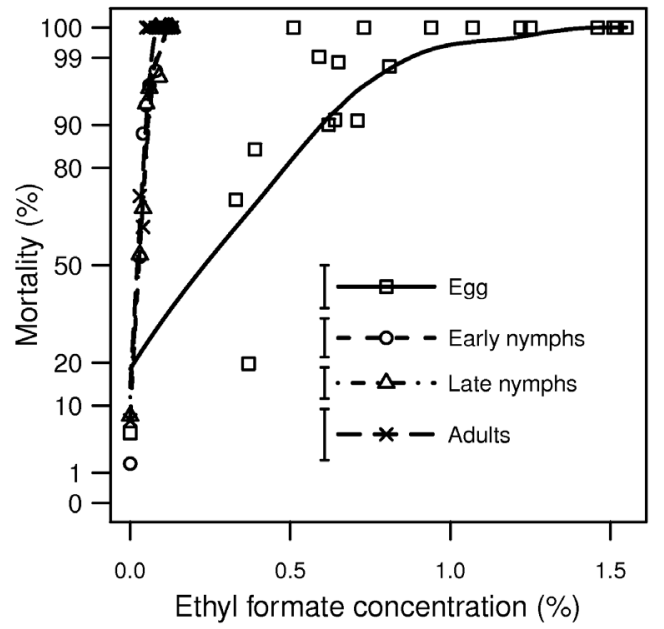

Figure 2 Mortality (\%) of different life stages of tomato potato psyllids after a 1-h exposure to different concentrations of ethyl formate.

\section{DISCUSSION}

$\mathrm{EF}+\mathrm{CO}_{2}$ is a promising postharvest treatment to control TPP on capsicums, tomatoes and tamarillos in New Zealand. A 1-h treatment of $0.09 \% \mathrm{EF}$ at $13^{\circ} \mathrm{C}$ achieved $99 \%$ mortality (upper 95\% confidence limit) of TPP nymphs and adults, whereas a higher concentration was required for TPP egg control. There was variation in mean lethal concentration estimates for $99 \%$ mortality of eggs

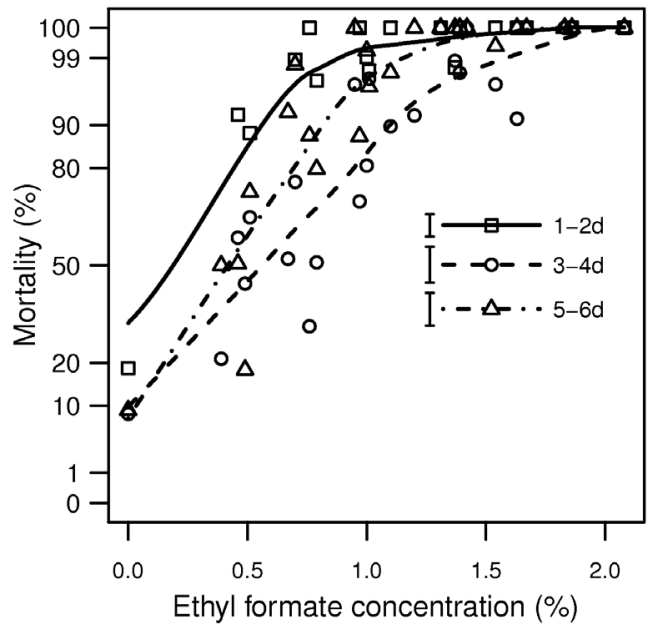

Figure 3 Mortality (\%) of different ages (days) of tomato potato psyllid eggs after a 1-h exposure to different concentrations of ethyl formate.

for a $1 \mathrm{~h}$ treatment in the three trials $(1.15,0.81$ and 0.98-1.52\% EF for trials 1, 2 and 3, respectively). As outlined in the methods, assessment of egg mortality was altered between trials 2 and 3 to better reflect the post-hatch treatment effects on nymph survival. In trial 3 only live nymphs were assessed as eggs that had survived EF treatment and this may explain why the lethal EF concentration estimates are higher in trial 3. Although mean lethal

Table 2 Calculated lethal concentrations (\%) of ethyl formate to achieve 99\% mortality (LC99) of different life stages of tomato potato psyllid. Confidence intervals (CI) and standard errors (SEM) also presented.

\begin{tabular}{lccccccc}
\hline Life stage & Rep.1 & Rep.2 & Rep.3 & Rep.4 & Mean & 95\% CI & SEM $^{1}$ \\
\hline Eggs & 0.845 & 1.009 & 0.824 & 0.620 & 0.812 & $0.666-0.991$ & 0.082 \\
Early nymphs & 0.059 & 0.057 & 0.081 & 0.073 & 0.067 & $0.055-0.082$ & 0.005 \\
Late nymphs & 0.094 & 0.069 & 0.067 & 0.069 & 0.074 & $0.061-0.090$ & 0.006 \\
\hline
\end{tabular}

${ }^{1}$ SEMs are on a log scale

Table 3 Calculated lethal concentrations (\%) of ethyl formate to achieve 99\% mortality ( $\mathrm{LC}_{99}$ ) of different ages of tomato potato psyllid eggs. Confidence intervals (CI) and standard errors (SEM) also presented.

\begin{tabular}{lccccccc}
\hline $\begin{array}{l}\text { Egg age } \\
\text { (days) }\end{array}$ & Rep.1 & Rep.2 & Rep.3 & Rep.4 & Mean & 95\% CI & SEM \\
\hline $1-2$ & 1.34 & 0.71 & 1.00 & - & 0.98 & $0.76-1.28$ & 0.18 \\
$3-4$ & 1.62 & 1.26 & 1.62 & 1.60 & 1.52 & $1.20-1.91$ & 0.09 \\
$5-6$ & 1.05 & 0.80 & 1.15 & 1.07 & 1.01 & $0.80-1.27$ & 0.08 \\
\hline
\end{tabular}


concentration estimates for different egg ages were not significantly different, they did range from ca $1 \% \mathrm{EF}$ for young and older eggs to $1.5 \% \mathrm{EF}$ for mid-aged eggs, which in practical terms, is a notable difference, and warrants further investigation. Regardless, TPP eggs are the most tolerant life stage and require a $1 \mathrm{~h}$ treatment of $>1.5 \% \mathrm{EF}$ to achieve $>99 \%$ mortality.

Various studies have found the efficacy of fumigants on pest insect eggs to be related to egg age, with most pest eggs having higher tolerance when less than 3 days old, compared with eggs older than 3 days (Bell 1976; Williams \& Sprenkel 1990; Bell \& Savvidou 1999; Papachristos \& Stamopoulos 2004), although this is not necessarily the case for every species, with some pests showing no difference in egg-age tolerance to fumigants (Simpson et al. 2007).

Initial fruit quality trials indicated that both capsicums and truss tomatoes can tolerate 0.4$0.8 \% \mathrm{EF}+\mathrm{CO}_{2}$, although $\geq 1.2 \% \mathrm{EF}$ resulted in a significant stem browning and reduction in fruit quality in capsicums (Redpath et al. 2015) and truss tomatoes (S.R. Olsson, Plant \& Food Research, unpublished data). In semicommercial studies, tamarillos were more tolerant than capsicums and truss tomatoes, and results suggested that tamarillos were able to tolerate $1 \% \mathrm{EF}\left(+\mathrm{CO}_{2}\right)$ topped up for $1-2 \mathrm{~h}$ (Jamieson et al. 2014a).

This work should also consider the effectiveness on other market access pests (e.g. mites, mealybugs, thrips, scale insects and spiders), as their interception during phytosanitary inspection can result in 'rejection or fumigation' of capsicum consignments. A 1-hour 1-1.5\% EF treatment has the potential to control other pests that are susceptible to EF treatment, such as some species of thrips and scale insects and mobile life stages of some mealybug and mite (Chhagan et al. 2013; Griffin et al. 2013; Jamieson et al. 2014b, c).

Further semi-commercial trials indicated that although complete control of TPP adults and nymphs can be achieved with EF treatments that capsicums and truss tomatoes can tolerate, only high mortalities ( $>92 \%$ ) of eggs can be achieved with a $1 \%$ EF treatment topped up for $1 \mathrm{~h}$ (L.E. Jamieson, unpublished data). Thus, further demonstration is required of low egg prevalence and low survival on the fruit and stem (N.E.M. Page-Weir, unpublished data), combined with the efficacy of other postharvest pest mitigation measures against TPP eggs, such as high pressure washing (Page-Weir et al. 2015) and/or hot water treatment (M.J. Griffin, unpublished data), to be confident of sufficient control to replace methyl bromide as a quarantine treatment for capsicums and truss tomatoes.

Further research is warranted on the effects of high pressure washing, hot water treatment, and EF to develop a systems approach to replace methyl bromide fumigation for TPP.

\section{ACKNOWLEDGEMENTS}

Thanks to Vegetables New Zealand, the Ministry for Business, Innovation and Employment Vegetable Core Programme and Market Access Fresh Fruit Programme (CO6X0709) for financially supporting this research. We also gratefully acknowledge Robin Gardner-Gee and Aleise Puketapu for assisting with rearing TPP.

\section{REFERENCES}

Bell CH 1976. The tolerance of developmental stages of four stored product moths to phosphine. Journal of Store Products Research 12: 77-86.

Bell CH, Savvidou N 1999. The toxicity of Vikane (sulfuryl floride) to age groups of eggs of the Mediterranean flour moth (Ephestia kuehniella). Journal of Stored Products Research 35: 233-247.

Chhagan A, Jamieson LE, Griffin MJ, PageWeir NEM, Poulton J, Zulhendri F, Feng R, Connolly PG, Davis VA, Olsson S, Redpath SP, Kean AM, Woolf AB 2013. Postharvest management of New Zealand flower thrips (Thrips obscuratus) on apricots using ethyl formate or pyrethrum-based treatments. New Zealand Plant Protection 66: 63-74.

Cleveland WS, Grosse E, Shyu WM 1992. Local regression models. Chapter 8. In: Chambers JM, Hastie TJ ed. Statistical Models in S. Wadsworth \& Brooks/Cole, CA, USA. Pp. 309-376. 
Griffin MJ, Jamieson LE, Chhagan A, PageWeir NEM, Poulton J, Davis VA, Zulhendri F, Connolly PG 2013. The potential of ethyl formate + carbon dioxide to control a range of horticultural pests. New Zealand Plant Protection 66: 54-62.

Hastie TJ, Pregibon D 1992. Generalized linear models. Chapter 6. In: Chambers JM, Hastie TJ eds. Statistical Models in S. Wadsworth \& Brooks/Cole. Pp. 196-248.

Jamieson L, Page-Weir N, Chhagan A, Connolly P, Poulton J, Kean A 2013. The potential of using low oxygen and ethyl formate or ethyl acetate to disinfest fresh fruit in storage. New Zealand Plant Protection 66: 45-53.

Jamieson L, Page-Weir N, Redpath S, Griffin M, Chhagan A, Olsson S, Woolf A 2014a. Scaling up of ethyl formate $+\mathrm{CO}_{2}$ treatment to disinfest capsicums, truss tomatoes and tamarillos targeting tomato/potato psyllid. Plant \& Food Research Report No. 10750. Plant \& Food Research, Auckland, New Zealand. 42 pp.

Jamieson LE, Griffin M, Page-Weir NEM, Chhagan A, Redpath S, Connolly PG 2014b. Developing ethyl formate treatment for disinfesting pipfruit. New Zealand Plant Protection 67: 96-102.

Jamieson LE, Griffin MJ, Chhagan A, PageWeir NEM, Redpath SP, Olsson S, Connolly PG, Woolf $\mathrm{AB}$ 2014c. Advances in the development of ethyl formate + carbon dioxide to control pests of horticultural commodities. International Horticultural Congress, 17-22 August 2014, Brisbane, Queensland, Australia.

Jamieson LE, Meier X, Page BBC, Zulhendri F, Page-Weir NEM, Brash D, McDonald RM, Stanley J, Woolf AB 2009. A review of postharvest disinfestation technologies for selected fruits and vegetables. Plant \& Food Research Report No. 36072. Plant \& Food Research, Auckland, New Zealand. 179 pp.

MPI 2014. Potato/Tomato Psyllid Bactericera cockerelli. http://www.biosecurity.govt.nz/ pests/potato-tomato-psyllid (accessed 10 April 2015).
Papachristos DP, Stamopoulos DC 2004. Fumigant toxicity of three essential oils on the eggs of Acanthoscelides obtectus (Say) (Coleoptera : Bruchidae). Journal of Stored Products Research 40: 517-525.

Page-Weir NEM, Jamieson LE, Radpath SR, Griffin MJ, Olsson SR, Chhagan A, Biswas P, Woolf AB 2015. High-pressure-washing to manage insect infestations on capsicums. New Zealand Plant Protection 68: 348-352.

RCore Team 2013. R: A language and environment for statistical computing. R Foundation for Statistical Computing, Vienna, Austria.

Redpath SP, Jamieson LE, Olsson S, Page Weir NEM, Griffin M, Chhagan A, Woolf $A B$ 2015. Tolerance of capsicums to ethyl formate applied as a disinfestation treatment. Plant \& Food Research Report No. 11522. Plant \& Food Research, Auckland, New Zealand. 20 pp.

Ryan R, Bishop S 2003. VAPORMATE ${ }^{\mathrm{m}}$ : nonflammable ethyl formate /liquid carbon dioxide fumigant mixture. In: Wright EJ, Webb MC, Highley E ed. Stored grain in Australia 2003. Proceedings of the Australian Postharvest Technical Conference, Canberra, 25-27 June 2003. CSIRO Stored Grain Research Laboratory, Canberra. Pp. 190-192.

Simpson T, Bikoba V, Tipping C, Mitcham E 2007. Ethyl formate as a postharvest fumigant for selected pests of table grapes. Journal of Economic Entomology 100: 1084-1090.

Tran LT 2012. Population phenology, life table and forecasting models of tomato-potato psyllid (Bactericera cockerelli) and the efficiency of a selected natural enemy for its control. PhD thesis, Lincoln University, New Zealand. $121 \mathrm{pp}$.

US FDA 2015. GRAS Substances (SCOGS) Database. http://www.fda.gov/food/ ingredientspackaginglabeling/gras/scogs/ ucm2006852.htm (accessed 10 April 2015).

Williams LH, Sprenkel RJ 1990. Ovicidal activity of sulfuryl fluoride to anobiid and lyctid beetle eggs of various ages. Journal of Entomological Science 25: 366-375. 